\title{
Comparison of Histological Changes in Normal and RFM Affected Cows Treated with Uterine Ecbolics and Ovsynch Protocol
}

\author{
S. Alagar*, C. Velladurai, M. Selvaraju and R. Ezakial Napolean \\ Department of Veterinary Gynaecology and Obstetrics, Veterinary College and Research \\ Institute, Namakkal-2, Tamil Nadu, India \\ *Corresponding author
}

\section{A B S T R A C T}

\section{Keywords}

Cows, Endometrium, Uterine ecbolics,

Ovsynch, RFM and Histology

Article Info

Accepted:

07 February 2018

Available Online:

10 March 2018
Endometrial histopathology was studied in 24 cows on day 2 postpartum in group I and II were treated with an intramuscular injection of $25 \mathrm{mg} \mathrm{PGF} 2 \alpha$ and 50 IU oxytocin respectively. Whereas in group III cow selected at day 35-50 post-partum RFM affected cows treated with TANUVAS mineral mixture plus ovsynch protocol. Histopathology of the uterus in the RFM affected cows before treatment reveals complete loss of epithelial lining of endometrium, whereas after treatment Proliferations of epithelial lining of endometrium were evident. In group I and II on day 10 postpartum, showed involution process, with mild neutrophilic and mononuclear infiltration. When compared to day 10 postpartum, the regenerative changes of epithelium and endometrial glandular activities were predominant on day 30 postpartum in experimental groups especially in group I cows followed by group II.

\section{Introduction}

In bovine practice, uterine biopsies were first described in 1948 and the technique and equipment for endometrial biopsy were described in 1951 (Miller, 1951). Uterine biopsy was a valuable diagnostic tool in identifying morphological alterations in the uterine endometrium (Prasad and Krishna, 2009). During the examination of the endometrial biopsy, inflammatory, periglandular fibrosis and cystic glandular degeneration were studied to provide prognosis for cow fertility (Singh et al., 1983). The endometrium of all mammals is richly endowed with glands that open on to the luminal surface. The endometrial glands secrete a variety of molecules, collectively termed as histotroph or uterine milk that is essential for maternal support of conceptus survival and growth in mammals (Gray et al., 2001).

Pathak and Bansal (2012) observed that the endometrial glands were simple or branched tubular glands of which few were coiled distally. They were lined with simple columnar epithelium. These glands were more active during the follicular phase as compared to the luteal phase of the oestrous cycle. But the secretary activity was more pronounced during the luteal phase. Raja et al., (2012) 
reported that the histopathology of endometrium showed marked cellular changes of different degrees such as glandular hyperplasia, degenerative changes of the endometrium, cystic dilatation, mononuclear infiltration and perivascular fibrosis. Hence, the present investigation was formulated to study the effect of ovsynch treatment and uterine ecbolic drugs on endometrial regeneration and normally calved cows.

\section{Materials and Methods}

An experiment was conducted in Holstein Friesian (HF) crossbred cows which were brought to the Large Animal Gynaecology unit of Teaching Veterinary Clinical Complex (TVCC), Veterinary College and Research Institute, Namakkal. Normally calved 24 healthy Holstein Friesian crossbred cows aged between $2^{\text {nd }}$ and $5^{\text {th }}$ lactations were selected immediately. Day of parturition was considered as day 0 of the experiment. On day 2 postpartum, cows of group I and II were treated with an intramuscular injection of 25 $\mathrm{mg} \mathrm{PGF}_{2} \alpha$ (Dinoprost Tromethamine, 5ml, Lutalyse $^{\circledR}$, Pfizer Animal Health India Ltd, India), 50 IU oxytocin $\left(10 \mathrm{ml}\right.$, Syntophar ${ }^{\circledR}$, Interphar Healthcare Pvt. Ltd., Chandigarh, India), in group III animals was selected at 3550 days postpartum and treated with orally with TANUVAS mineral mixture daily @ 3050 grams for 15 days. At the end of mineral mixture supplementation cows of both the groups were treated with ovsynch protocol. The protocol included administration of $10 \mu \mathrm{g}$ of GnRH intramuscularly $(2.5 \mathrm{ml}$, Buserelin acetate, Ovulanta $^{\circledR}$, Vet Mankind, New Delhi) on the day of start of synchronization (day 0), $500 \mu \mathrm{g}$ of $\mathrm{PGF}_{2} \alpha$ intramuscularly $(2 \mathrm{ml}$, Cloprostenol, Pragma ${ }^{\circledR}$, INTAS, Ahmedabad) seven days later (day 7), another $10 \mu \mathrm{g}$ of GnRH intramuscularly $48 \mathrm{~h}$ after $\mathrm{PGF}_{2} \alpha$ (day 9) and timed artificial insemination (TAI) was done at 16 to 18 hours after the second $\mathrm{GnRH}$ injection (day 10).

\section{Endometrial biopsy procedures}

Albuchin's uterine biopsy catheter (Plate. 1) was used to obtain endometrial biopsy samples as per the technique followed by Palanisamy (2012) with slight modifications. The closed, sterilized biopsy catheter was introduced into the uterus adopting aseptic technique. The biopsy catheter was advanced into one of the uterine horns of uterus and the catheter was opened. The uterine wall was pressed with the thumb against the opening of the catheter. The catheter was closed, rotated and retracted slowly. Slight pressure was applied against catheter to prevent haemorrhage before retracting the instrument.

A piece of endometrium was released from the cutting edge of the catheter into a vial containing Bouin's fluid and stored for 24 hours and processed by routine paraffin technique and stained with haematoxylin and eosin as per technique described by Bancroft and Gamble (2008). Endometrial biopsy was taken from the all experimental and control cows on (i) day10 and (ii) day 30postpartum in group I and II, whereas in group III at the (i) time of animal selection and (ii) at AI.

\section{Results and Discussion}

In experimental group I (Fig. 1) and II (Fig. 2 ), on day 10 postpartum, the endometrium showed involution process, with mild neutrophilic and mononuclear infiltration. The mucin secretion was also noticed. The increased endometrial glandular activity was seen. Focal mild mononuclear infiltration and mild fibrosis were seen in few cases. Squamous metaplasia of uterine epithelium was noticed in one cow.

These regenerative changes of endometrium onday 10 postpartum were prominent in group I $\left(\mathrm{PGF}_{2} \alpha\right.$ group) followed by group II (oxytocin). 


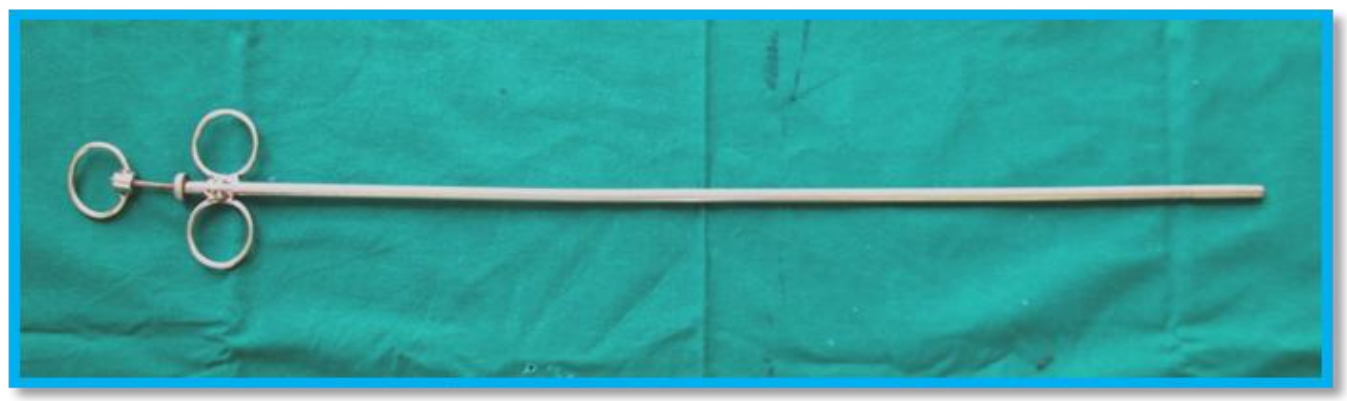

Plate.1a Albuchin's uterine biopsy catheter-with closed cut edge

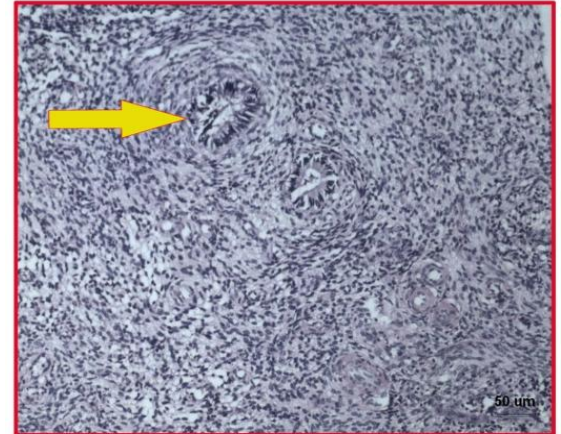

Group I - Day 10

Fig. 1

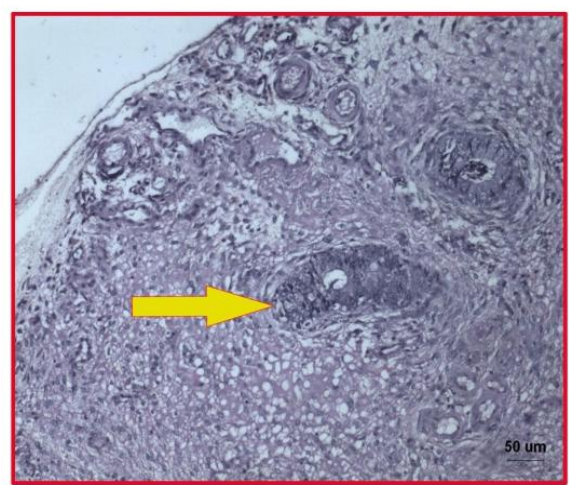

Group II - Day 10

Fig. 3

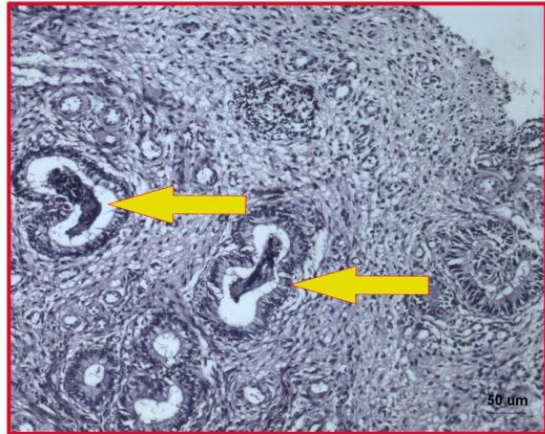

Group I - Day 30

Fig. 2

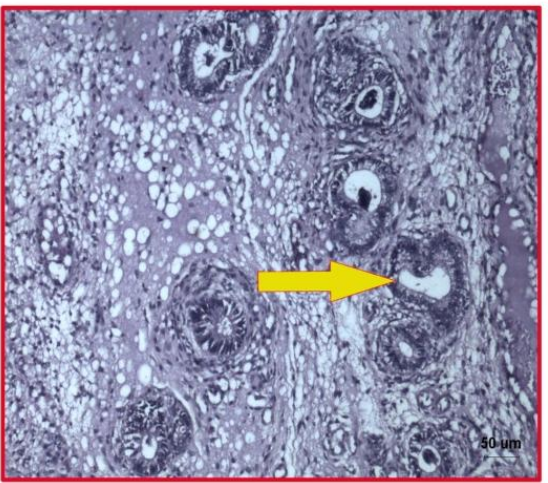

Group II - Day 30

Fig. 4

\section{Indicates endometrial gland and its secretory activity}

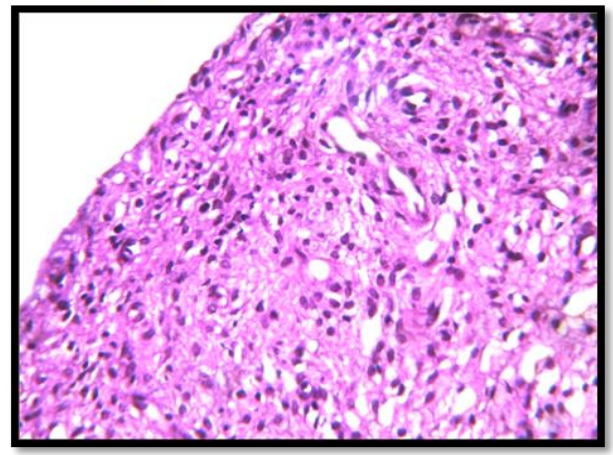

Fig. 5

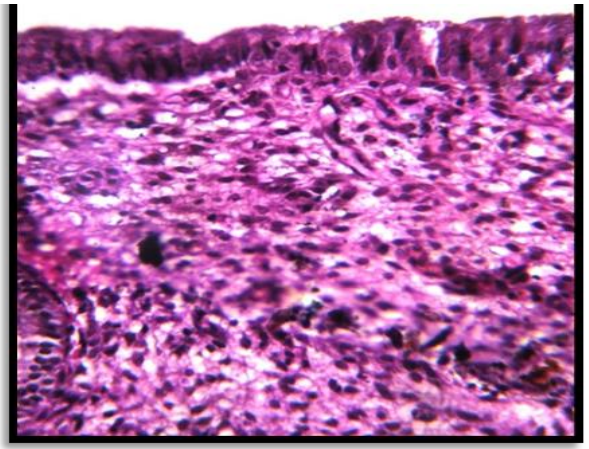

Fig. 6

Complete loss of epithelial linings intact endometrium with proliferating epithelial cells 
On day 30 postpartum, many uterine ecbolics treated cows had increased glandular activity with extensive lymphocytic infiltration and increased vascular spaces. The glandular secretion was predominant in few cases. Moderate neutrophilic and mononuclear infiltration was noticed. Few cows showed the presence of fibrous tissue.

When compared to day 10 postpartum, the regenerative changes of epithelium and endometrial glandular activities were predominant on day 30 postpartum in experimental groups especially in group I cows (Fig. 3) followed by group II (Fig. 4). Histopathology of the uterus in the RFM affected cows before treatment reveals discontinuation of the endometrial epithelial lining (Fig. 5). Complete loss of epithelial lining associated with degenerative changes and atrophied glandular acini and loss of epithelial cells in the endometrial glands.

However, after treatment proliferations of epithelial lining of endometrium (Fig. 6) and engorged blood vessels with active glandular acini of the endometrial glands are evident in RFM affected cows.

The endometrium of the normally calved cows of the present study appeared normal prior to treatment and it was in accordance with the findings of Singh et al., (1997) in buffaloes. In this study, on day 10, postpartum uterine lining epithelium was found to be normal with pseudo stratified columnar type. Endometrium showed involution process with mild neutrophilic and mononuclear infiltration. The endometrial glandular activity was seen in few cases with increased vascular spaces. On day 30 postpartum there was an increased endometrial glandular activity with extensive lymphocytic infiltration. These observations were in accordance with the findings of Prasad and Krishna (2009) in postpartum normally calved cows. The complete loss of epithelial layer, degeneration changes of endometrium, distorted endometrium and atrophic changes in the endometrial glands of RFM affected cows (III) before oestrus induction indicated the probable damage caused by RFM which is not noticed in the $\mathrm{NC}$ cows. These findings were in accordance and comparable with the reports of Prasad and Krishna (2009) in cows affected with RFM which showed clear regeneration of endometrium and its glandular acini after treatment.

Endometrial regeneration was evident and resumption of ovarian activity resulted in the oestrus induction in RFM affected cows which was well supported by the findings of Prasad and Krishna (2009) who proved that uterus had the powerful system of natural repair and recovery with the stimulated uterine defence mechanism.

\section{References}

Bancroft, J. D., and Gamble, M. 2008. Theory and practice of histological techniques. $6^{\text {th }}$ ed., Churchill Livingston, Elsevier, Philadelphia.

Gray, C. A., K. M. Taylor, W. S. Ramsey, J. R. Hill, F. W. Bazer, F. F. Bartol and Spencer, T. E. 2001. Histomorphology of the endometrial gland of buffalo. Biol. Reprod, 64: 1608.

Miller, J.G. 1951. A technique of endometrial biopsy in the bovine animal. $J$. American Vet. Med. Assoc., 119: 368370.

Palanisamy, M., 2012. Efficacy of immunomodulators, Lugol's iodine and prostaglandin $\mathrm{F}_{2} \alpha$ in the treatment of post-partum endometritis in cows. Ph.D., thesis submitted to Tamil Nadu Veterinary and Animal Sciences University, Chennai.

Pathak, D., and Bansal, N. 2012. Histomorphology of the endometrial 
gland of Buffalo. Indian Vet. J., 89: 2528.

Prasad, B. C., and Krishna, K. M. 2009.Effect of RFM on histomorphology of uterine endometrium in cross bred cows. Tamil Nadu J. Vet. Anim. Sci., 5: 164-166.

Raja, S., T. G. Devanathan, K. Kulasekar, N. Pazhanivel and Balachandran, C. 2012. Whiteside test and endometrial biopsy for diagnosis of endometritis in repeat breeding cows. Indian J. Anim. Reprod., 33: $56-58$
Singh, G., G.B. Singh, R.D. Sharma and A.S. Nanda, 1983. Experimental treatment of summer anestrus buffaloes with norgestomet and PRID. Theriogenology, 19: 323-329.

Singh, J., R. A. Pierson and Adams, G. P. 1997. Ultrasound images attributes of the bovine corpousluteum: structural and functional correlates. J. Reprod. Fertil, 109: 35-44.

\section{How to cite this article:}

Alagar, S., C. Velladurai, M. Selvaraju and Ezakial Napolean, R. 2018. Comparison of Histological Changes in Normal and RFM Affected Cows Treated with Uterine Ecbolics and Ovsynch Protocol. Int.J.Curr.Microbiol.App.Sci. 7(03): 513-517. doi: https://doi.org/10.20546/ijcmas.2018.703.061 